\title{
Thromboelastography in Venovenous Extracorporeal Membrane Oxygenation for Acute Respiratory Distress Syndrome
}

\author{
Sarvesh Pal Singh ${ }^{1}$ Yogesh Solanki ${ }^{1}$ Poonam Malhotra Kapoor ${ }^{2}$ \\ ${ }^{1}$ Department of CTVS, All India Institute of Medical Sciences, \\ New Delhi, India \\ 2Department of Cardiac Anaesthesia, All India Institute of Medical \\ Sciences, New Delhi, India \\ Address for correspondence Sarvesh Pal Singh, MD, DM, FIACTA, FTEE, \\ Department of CTVS, CTC, All India Institute of Medical Sciences, \\ New Delhi 110029, India (e-mail: sarveshpal.singh@gmail.com). \\ J Card Crit Care TSS 2017;1:101-104
}
Abstract
Keywords
- acute respiratory distress syndrome
- thromboelastography
- venovenous extra- corporeal membrane oxygenation

The authors hereby report the case of a 16-year-old girl who was put on venovenous extracorporeal membrane oxygenation (ECMO) for refractory acute respiratory distress syndrome. Use of thromboelastography as a supplement to conventional hemostatic investigations is highlighted to achieve an optimal anticoagulation state during the ECMO.

\section{Introduction}

Venovenous extracorporeal membrane oxygenation (VV ECMO) is being used for treatment of refractory acute respiratory distress syndrome (ARDS). It has been shown to improve outcomes in patients with respiratory failure. ${ }^{1-3}$ Unfractionated heparin (UFH) is the most widely used agent to maintain anticoagulation in ECMO. The therapeutic effect of UFH is monitored by activated coagulation time (ACT) and activated partial thromboplastin time (aPTT). However, recent experiences have suggested that even when both these parameters are in desired ranges, patients still carry a risk of bleeding or circuit thrombosis. ${ }^{4}$ Thromboelastography (TEG) is a viscoelastic hemostatic test that provides overall information on clot initiation, clot kinetics, and resolution of the clot. The authors hereby report the case of 16-year-old girl in whom TEG revealed a hypercoagulable state when ACT and aPTT were in desired range.

\section{Case Report}

A 16-year-old girl was admitted with history of maculopapular eruptions all over her body and pneumonia. She developed ARDS within 24 hours of admission with a Murray score of 4.0 and was unable to maintain a saturation of $>85 \%$.
A VV ECMO, with a right femoral vein inflow cannula (21F) and a right internal jugular outflow cannula (17F), was initiated. After initiation of $\mathrm{ECMO}$, her $\mathrm{PaO}_{2}$ stabilized between 50 and $60 \mathrm{~mm} \mathrm{Hg}$. The ECMO flow was $2.5 \mathrm{~L} / \mathrm{min}$ with a $\mathrm{FiO}_{2}$ on ECMO of $100 \%$. UFH was given in a bolus of $100 \mathrm{U} / \mathrm{kg}$ at the time of cannulation, and an infusion of heparin was started at $10 \mathrm{U} / \mathrm{kg} / \mathrm{h}$ to maintain ACT of 170 to 200 seconds. The following cutoffs were followed: platelet $100,000 / \mu \mathrm{L}$, international normalized ratio (INR) $<1.5$, aPTT 45 to 70 seconds, ACT 170 to 200 seconds, and fibrinogen $>200 \mathrm{mg} / \mathrm{dL}$.

Broad-spectrum antibiotics for gram-positive and gramnegative bacteria were started following which the patient started improving on day 3 of ECMO. Initially, she was given enteric feeding, and in view of prolonged ventilation, a percutaneous tracheostomy was performed. The heparin infusion was stopped for 2 hours before performing the tracheostomy. As soon as the tracheostomy was completed, a bolus of $100 \mathrm{U} / \mathrm{kg}$ heparin was administered and the infusion was started on $10 \mathrm{U} / \mathrm{kg} / \mathrm{h}$. After 12 hours of tracheostomy, bleeding occurred from tracheostomy site (-Fig. 1). A TEG was performed to evaluate the coagulation function. The first TEG revealed an inadequate heparin effect, low platelet function, and a hypercoagulable state ( $\boldsymbol{- \text { Fig. }}$. 2A). The heparin was increased to $15 \mathrm{U} / \mathrm{kg} / \mathrm{h}$ to delay the initiation of clot formation (prolong the $\mathrm{R}$ and $\mathrm{K}$ time). A repeat TEG after 24 hours
Dol https://doi.org/ 10.1055/s-0038-1626677 ISSN 2457-0206.
Copyright @ 2017 Official Publication of The Simulation Society (TSS), accredited by International Society of Cardiovascular Ultrasound (ISCU)
License terms

()ㅜ(1) $\Theta \circledast$ 
still revealed a normal trace and the heparin was further increased to $20 \mathrm{U} / \mathrm{kg} / \mathrm{h}$. The third TEG ( - Fig. 2C) demonstrated the therapeutic effect of heparin and normal platelet function. The patient was weaned off ECMO 2 days later and the TEG trace shown in - Fig. 2D was recorded after decannulation and reversal with protamine. She improved steadily and

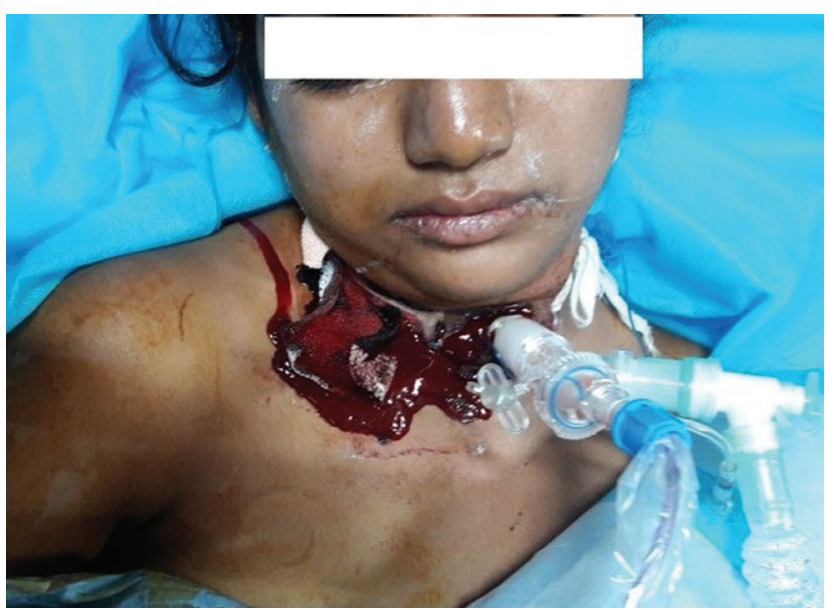

Fig. 1 Bleeding from tracheostomy site. was weaned off ventilation 10 days later. Her ECMO duration was 8 days and hospital stay was 28 days. She was doing well on her first follow-up.

\section{Discussion}

The trace of TEG displays a $\mathrm{R}$ time that relates to the initiation of clot formation (common, intrinsic, and extrinsic pathway), $\mathrm{K}$ time (time taken for the clot to reach up to $20 \mathrm{~mm}$ from $2 \mathrm{~mm}$, clot kinetics), maximum amplitude (80\% platelets and $20 \%$ fibrinogen), and $\alpha$ angle (rate of clot formation). ${ }^{5}$ Clot strength $(G)$ is the shear elastic modulus strength of clot and is expressed in dynes $/ \mathrm{cm}^{2}$. The normal values for (TEM-A Framar Biomedica, Hemologix) R time, K time, $\alpha$ angle, maximum amplitude, and $\mathrm{G}$ are 5 to 11 minutes, 1.5 to $4.5 \mathrm{~min}$ utes, 44 to 66 degrees, 53 to $70 \mathrm{~mm}$, and 5,500-12,000 dynes/ $\mathrm{cm}^{2}$, respectively.

At the initiation of ECMO, there is dilution of coagulation factors, and a consumption coagulopathy also ensues causing decrease in coagulation factors and fibrinogen levels. ${ }^{6,7}$ There is an immediate decrease in platelet count as well. ${ }^{8,9}$ Conventionally, the parameters measured during ECMO include platelets, PT, aPTT, fibrinogen, and ACT. Anti-factor Xa (fXa)

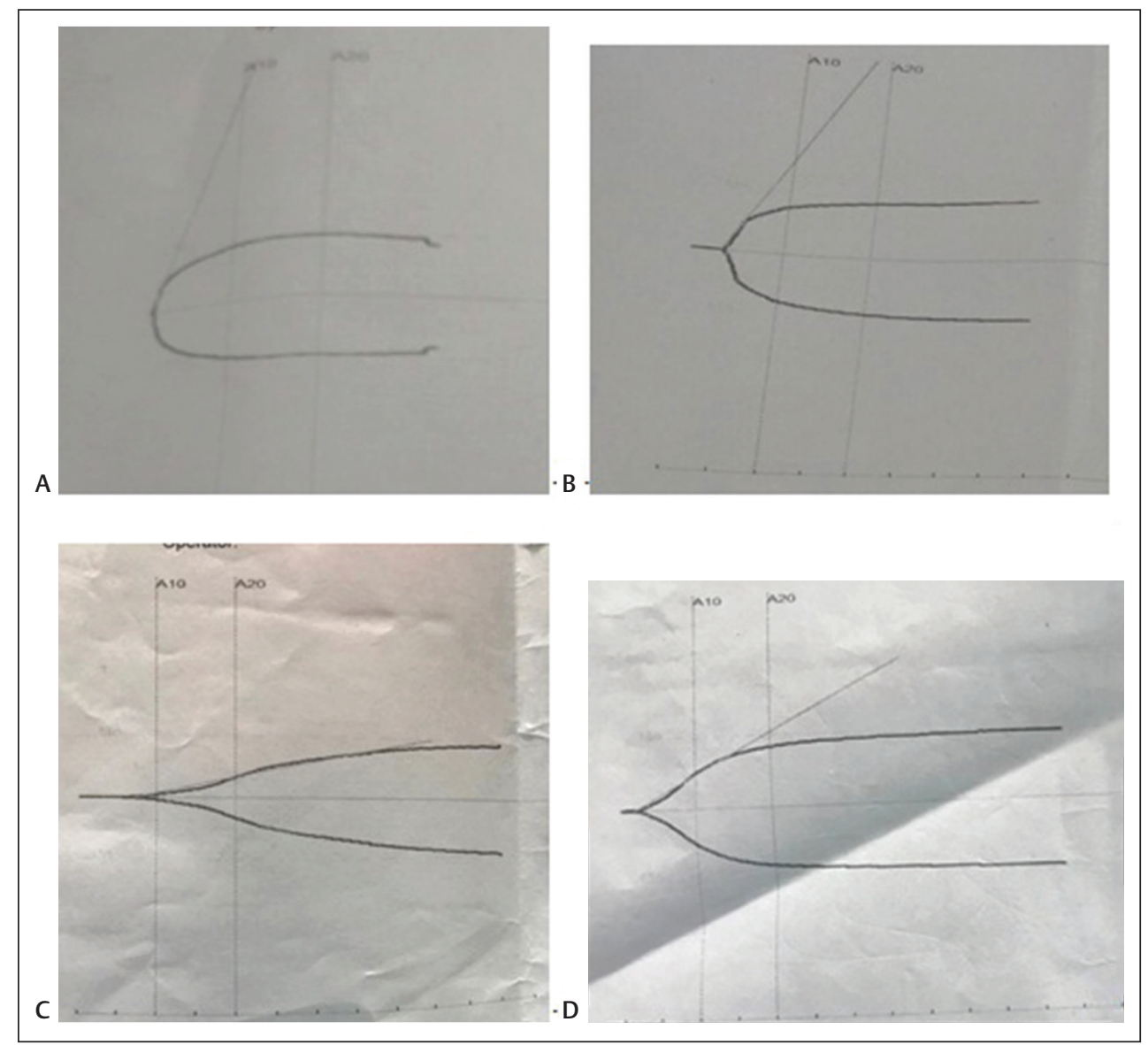

Fig. 2 Thromboelastography tracings. (A) Hypercoagulable state, (B) normalization of trace, (C) hypocoagulable state, (D) normal trace after reversal with protamine post decannulation of ECMO. 
Table 1 Thromboelastography parameters and hematological values of the patient

\begin{tabular}{|c|c|c|c|c|c|c|c|c|c|c|c|}
\hline \multirow[t]{2}{*}{ S. No. } & \multicolumn{6}{|c|}{ TEG parameters } & \multicolumn{5}{|c|}{ Laboratory parameters } \\
\hline & $\begin{array}{l}\text { R time } \\
\text { (min) }\end{array}$ & $\begin{array}{l}\text { K time } \\
\text { (min) }\end{array}$ & $\begin{array}{l}\alpha \text { angle } \\
\left({ }^{\circ}\right)\end{array}$ & $\begin{array}{l}\text { MA } \\
(\mathrm{mm})\end{array}$ & $\begin{array}{l}\text { TMA } \\
\text { (min) }\end{array}$ & $\begin{array}{l}\text { G (dynes/ } \\
\mathrm{cm}^{2} \text { ) }\end{array}$ & $\begin{array}{l}\text { Platelets } \\
(\mathrm{X} 1,000 / \mu \mathrm{L})\end{array}$ & PT (s) & $\begin{array}{l}\text { aPTT } \\
(s)\end{array}$ & $\begin{array}{l}\text { ACT } \\
(s)\end{array}$ & $\begin{array}{l}\text { Fibrinogen } \\
\text { level }(\mathrm{mg} / \mathrm{dL})\end{array}$ \\
\hline & & & & & & & 128 & \begin{tabular}{|l|}
12.5 \\
$(12)$ \\
\end{tabular} & \begin{tabular}{|l|}
70 \\
$(35)$ \\
\end{tabular} & 205 & 280 \\
\hline A & 0.8 & 1.2 & 74 & 37.8 & 13.39 & 3,013 & 102 & \begin{tabular}{|l|}
13.3 \\
$(12)$
\end{tabular} & \begin{tabular}{|l|}
45 \\
$(35)$
\end{tabular} & 168 & - \\
\hline$B$ & 4.0 & 1.5 & 69 & 46.0 & 38.77 & $4,371.7$ & 138 & \begin{tabular}{|l|}
14.2 \\
$(12)$ \\
\end{tabular} & $\begin{array}{l}37.4 \\
(30)\end{array}$ & 182 & - \\
\hline C & 11.5 & 11.3 & 18.74 & 44.3 & 55.16 & 4,048 & 153 & $\begin{array}{l}13.8 \\
(12) \\
\end{array}$ & $\begin{array}{l}46.8 \\
(30) \\
\end{array}$ & 198 & - \\
\hline $\mathrm{D}$ & 3.8 & 4.8 & 39.1 & 52.8 & 58 & $5,601.3$ & 92 & $\begin{array}{l}13.1 \\
(12)\end{array}$ & $\begin{array}{l}33.4 \\
(30)\end{array}$ & 154 & - \\
\hline
\end{tabular}

Abbreviations: ACT, activated coagulation time; aPTT, activated partial thromboplastin time; MA, maximum amplitude; TEG, thromboelastography; TMA, time to maximum amplitude.

levels and heparin levels $(0.2-0.4 \mathrm{U} / \mathrm{mL})$ may also be measured for direct evidence. The anticoagulation targets are less on VV ECMO as compared to venoarterial (VA) ECMO as the risk of ischemia of the limb is less. The cutoffs followed for VV ECMO include platelet 100,000/ $\mu \mathrm{L}$, INR < 1.5, aPTT 45 to 70 seconds, ACT 170 to 200 seconds, and fibrinogen $>200 \mathrm{mg} / \mathrm{dL}$

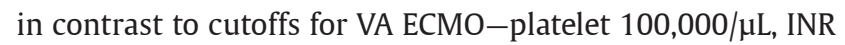
$<2.0$, aPTT 70 to 100 seconds, ACT 200 to 240 seconds, and fibrinogen $>150 \mathrm{mg} / \mathrm{dL}^{10}{ }^{10}$ In case of VV ECMO, the anticoagulation may be withheld for longer periods as well because the risk of stroke is not related to the circuit.

It has been demonstrated that aPTT correlates with anti-fXa levels, but there is no correlation between ACT and anti-fXa levels. ${ }^{11,12}$ Zmuda et al studied the relation between aPTT and anti-fXa levels. They found that, during heparin infusion, when the anti-fXa levels progressively increase to $0.1,0.2,0.3$, 0.4 , and $0.5 \mathrm{U} / \mathrm{mL}$, the baseline aPTT of 28 seconds increases to $30.4,39.8,51.1,66.8$, and 80.1 seconds, respectively. They also recorded that with anti-fXa levels of $0.1 \mathrm{U} / \mathrm{mL}$, the $\mathrm{R}$ and $\mathrm{K}$ times on TEG increase to approximately 3 and 10 times, respectively. In this patient, the authors kept on increasing the heparin infusion until the $\mathrm{R}$ and $\mathrm{K}$ times became 3 and 10 times of the normal, respectively ( - Table 1 ). At $20 \mathrm{U} / \mathrm{kg} / \mathrm{h}$ of heparin infusion, the TEG began to show a trace of optimal anticoagulation. Also, the aPTT was 46.8 seconds establishing an appropriate therapeutic value (1.5 times the control).

The TEG was done in view of bleeding from the tracheostomy site. Instead, it revealed a hypercoagulable state (-Fig. 2A). It was explainable as PT and fibrinogen were within normal limits and aPTT was subtherapeutic. As the authors increased the heparin infusion to $20 \mathrm{U} / \mathrm{kg} / \mathrm{h}$, the aPTT increased to therapeutic levels and TEG began to show a trace of optimal anticoagulation. However, if the PT time is prolonged and there is a hypercoagulable trace on TEG, a presumptive diagnosis of liver disease should be considered. The decrease in levels of Factor VII in liver disease may increase the PT.
In this patient, whose ACT is 168 seconds and aPTT is 45 seconds (control 35 seconds), TEG revealed a hypercoagulable state. There was a risk of circuit thrombosis and venous thromboembolism at such subtherapeutic anticoagulation. With increase in heparin dosing and repeated TEG, optimal anticoagulation was achieved and maintained till decannulation.

In conclusion, TEG supplemented the conventional tests of hemostasis to achieve an optimal anticoagulation state during the ECMO.

\section{References}

1 Abrams D, Brodie D. Extracorporeal membrane oxygenation for adult respiratory failure: 2017 Update. Chest 2017;152 (3):639-649

2 Song JH, Woo WK, Song SH, et al. Outcome of veno-venous extracorporeal membrane oxygenation use in acute respiratory distress syndrome after cardiac surgery with cardiopulmonary bypass. J Thorac Dis 2016;8(7):1804-1813

3 Combes A, Bréchot N, Luyt CE, Schmidt M. Extracorporeal membrane oxygenation: beyond rescue therapy for acute respiratory distress syndrome? Curr Opin Crit Care 2017;23(1):60-65

4 Sklar MC, Sy E, Lequier L, Fan E, Kanji HD. Anticoagulation practices during venovenous extracorporeal membrane oxygenation for respiratory failure. A systematic review. Ann Am Thorac Soc 2016;13(12):2242-2250

5 Bose E, Hravnak M. Thromboelastography: a practice summary for nurse practitioners treating hemorrhage. J Nurse Pract 2015;11(7):702-709

6 Oliver WC. Anticoagulation and coagulation management for ECMO. Semin Cardiothorac Vasc Anesth 2009;13(3):154-175

7 Plötz FB, van Oeveren W, Bartlett RH, Wildevuur CR. Blood activation during neonatal extracorporeal life support. J Thorac Cardiovasc Surg 1993;105(5):823-832

8 Robinson TM, Kickler TS, Walker LK, Ness P, Bell W. Effect of extracorporeal membrane oxygenation on platelets in newborns. Crit Care Med 1993;21(7):1029-1034

9 Stallion A, Cofer BR, Rafferty JA, Ziegler MM, Ryckman FC. The significant relationship between platelet count and haemorrhagic complications on ECMO. Perfusion 1994;9(4):265-269 
104 Thromboelastography in Venovenous ECMO for ARDS Singh et al.

10 Singh SP, Bansal A, Parakh N, et al. First successful experience of ECPR to heart transplant at a tertiary care institute. Indian J Thorac Cardiovasc Surg 2017

11 Panigada M, Artoni A, Passamonti SM, et al. Hemostasis changes during veno-venous extracorporeal membrane oxygenation for respiratory support in adults. Minerva Anestesiol 2016;82 (2):170-179
12 Zmuda K, Neofotistos D, Ts'ao CH. Effects of unfractionated heparin, low-molecular-weight heparin, and heparinoid on thromboelastographic assay of blood coagulation. Am J Clin Pathol 2000;113(5):725-731 